\title{
Estimation of the thermo-hydrodynamic parameters of the coolant in the Koshelev geothermal system
}

\author{
Dmitry Mamaev ${ }^{1 *}$ \\ ${ }^{1}$ Research Geotechnological Center, Far Eastern Branch of the Russian Academy of Sciences, \\ Petropavlovsk-Kamchatsky, Russia.
}

\begin{abstract}
The Koshelev geothermal system is located in the southern part of the Kamchatka Peninsula. On the surface, the system manifests itself by steam-hydrotherms at two thermal fields. Estimates of the predicted power from different data sources vary significantly, because the parameters of the coolant at great depths are not currently known and are presumable. Based on the available geological and geophysical data, a numerical threedimensional thermo-hydrodynamic model of the geothermal system has been developed. The model was calibrated according to thermometry data in exploratory wells. The calibrated model adequately describes the distribution of thermo-hydrodynamic parameters of the coolant in the system. It can be used to evaluate the coolant parameters during the development of the thermal resources of the Koshelev geothermal system. In the course of computational experiments, the developed model is used to obtain the distribution of the thermo-hydrodynamic parameters of the hydrothermal coolant in the geothermal system in the natural state and during the development of thermal resources.
\end{abstract}

\section{Introduction}

The Koshelev geothermal system is located in the southern part of the Kamchatka peninsula, $15 \mathrm{~km}$ east of the coast of the Sea of Okhotsk. It belongs to the PauzhetkoKambal-Koshelev geothermal region, which is part of the South Kamchatka geothermal province [1]. The Koshelevsky volcanic massif is composed of five volcanic structures of different ages, which are partially overlapping: Western, Valentine, Central, Eastern (Figure 1) and Ancient. The latter is buried under more young buildings.

On the surface, the geothermal system is manifested by unloading steam hydrotherms at two thermal fields. The Lower Koshelev thermal field is located on the slope of the Western volcano at elevations of $700-800 \mathrm{~m}$. The field area along the $20^{\circ} \mathrm{C}$ isotherm at a depth of $0.5 \mathrm{~m}$ is about $38,000 \mathrm{~m}^{2}$. The maximum temperature of thermal manifestations is $127{ }^{\circ} \mathrm{C}[2]$.

Upper Koshelev thermal field located in an erosion crater Valentin at elevations 1100 $1300 \mathrm{~m}$ [2]. The area of the field along the isotherm of $20^{\circ} \mathrm{C}$ at a depth of $0.5 \mathrm{~m}$ is about

\footnotetext{
* Corresponding author: ghtio@mail.ru
} 
$303,000 \mathrm{~m}^{2}$. The most typical form of thermal manifestations are powerful jets of superheated steam at a flow rate of $0.1-0.4 \mathrm{~kg} / \mathrm{s}$, at a temperature of $120-153^{\circ} \mathrm{C}$ [2]. There are more than 40 such jets, and the number of smaller ones is hundreds.

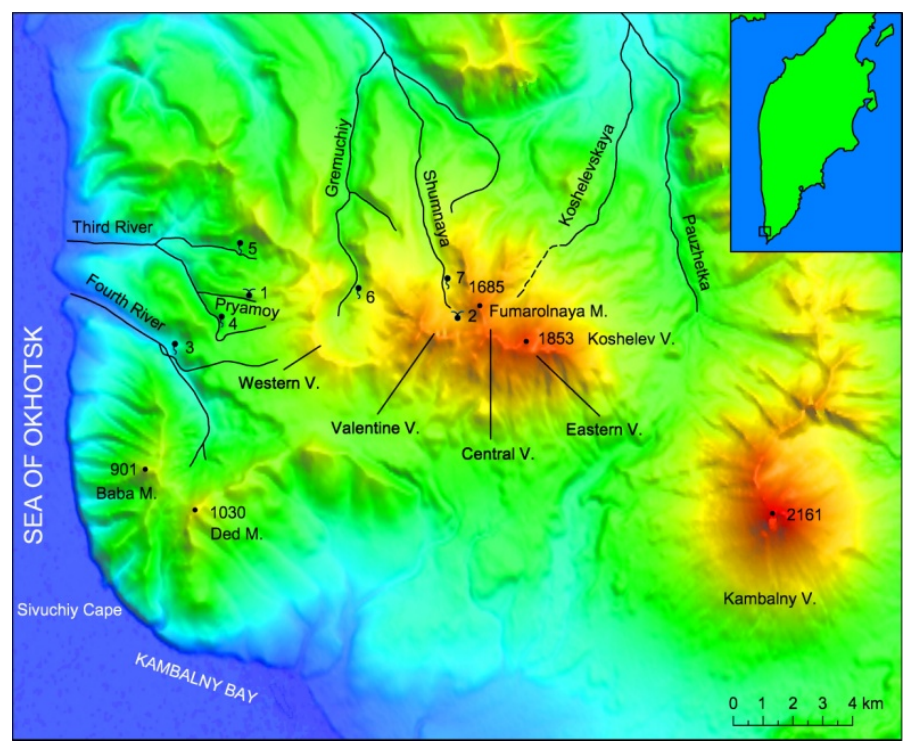

Fig. 1. Overview scheme of the Koshelevsky volcanic massif. Thermal fields: 1 - Lower Koshelev; 2 - Upper Koshelev. Thermal springs: 3 - Sivuchinskie; 4 - Promezhutochnye; 5 - Skazka; 6 Caldernye; 7 - Shumnye.

The table contains estimates of the forecast geothermal resources of the Lower Koshelev thermal field and the Koshelev geothermal system as a whole, according to data from various sources.

Table 1.

\begin{tabular}{|c|c|c|c|c|c|c|}
\hline \multirow[b]{3}{*}{ Data source } & \multirow{2}{*}{\multicolumn{2}{|c|}{ Natural heat transfer, MW }} & \multicolumn{4}{|c|}{ Forecast electric power, MW } \\
\hline & & & \multicolumn{2}{|c|}{$\begin{array}{l}\text { The whole of the } \\
\text { Koshelev system }\end{array}$} & \multicolumn{2}{|c|}{ Lower Koshelev field } \\
\hline & $\begin{array}{c}\text { The whole of } \\
\text { the Koshelev } \\
\text { system }\end{array}$ & $\begin{array}{c}\text { Lower } \\
\text { Koshelev field }\end{array}$ & 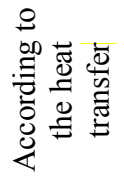 & 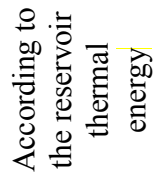 & 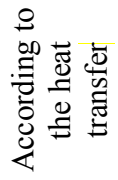 & 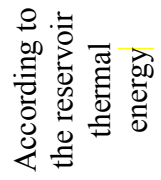 \\
\hline [2] & 306 & 105 & - & - & 30 & - \\
\hline [3] & - & - & - & 87 & - & - \\
\hline [4] & - & - & 144 & $215 \pm 64$ & 48 & $100 \pm 30$ \\
\hline [5] & - & - & & 943 & - & - \\
\hline
\end{tabular}

Estimates of the predicted power for different data sources vary significantly. It should be noted that calculations based on the thermal energy of the reservoir are approximate. The characteristics of the reservoir and coolant at great depths to the present time are largely presumed [4]. In this paper, the distribution of thermo-hydrodynamic parameters of the coolant in the Koshelev geothermal system is established using a model calibrated according to actual data. 


\section{Materials and methods}

A set of available data on the geological structure of the Koshelev geothermal system was used to construct its numerical three-dimensional thermo-hydrodynamic model. Calibration of the developed model, performed on the basis of exploratory drilling data, ensures the adequacy of the model to the object of investigation. In the course of computational experiments, the developed model is used to obtain the distribution of the thermohydrodynamic parameters of the hydrothermal coolant in the rocks of the geothermal system in the natural state and during the development of thermal resources. For the thermo-hydrodynamic calculations of the parameters of the geothermal fluid, the HYDROTHERM program [6] was used, which is capable of performing numerical threedimensional modeling of heat and mass transfer processes in a porous medium in the temperature range $0-1200^{\circ} \mathrm{C}$ and pressures of $0.05-1000 \mathrm{MPa}$, which allows using it for supercritical thermodynamic conditions.

The modeling area is a rectangular parallelepiped measuring $17 \mathrm{~km}$ in latitudinal direction, $6.8 \mathrm{~km}$ in meridional and $9.3 \mathrm{~km}$ in vertical direction (Fig. 2). The lower boundary of the modeling area is the horizontal plane at a depth of $7400 \mathrm{~m}$ below sea level. The upper limit of the models is set so that the maximum in the terrain of $1853 \mathrm{~m}$ falls into the modeling area - this is the plane at an altitude of $1864 \mathrm{~m}$ above sea level.

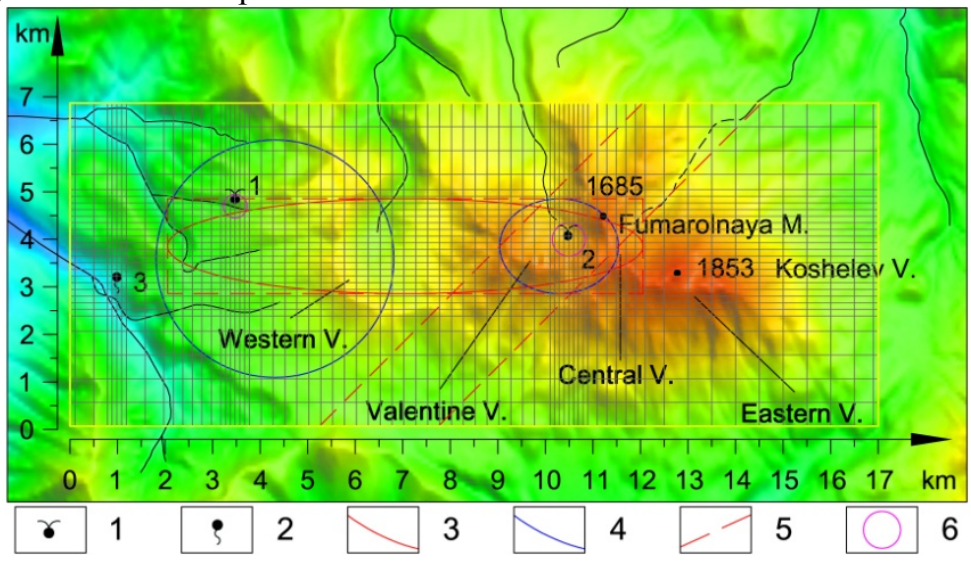

Fig. 2. Modeling area and computational grid. 1 - thermal fields with steam jets ( 1 - Lower Koshelev, 2 - Upper Koshelev); 2 - thermal springs (3 - Sivuchinskie); 3 - boundary of the magma chamber; 4 boundaries of subvolcanic intrusions; 5 - boundaries of tectonically disturbed zones; 6 - thermally withdrawing channels.

Three-dimensional numerical thermo-hydrodynamic models of the Koshelev geothermal system are constructed on the basis of analysis of available geological and geophysical data [2, 3, 7-13] and physical properties of rocks [14-18]. The structure of the models in the section is shown in Fig. 3.

The boundary conditions are defined as follows: on the lower and lateral boundaries of the modeling area, there is no flow of heat and fluid; on the day surface - a constant temperature of $10^{\circ} \mathrm{C}$ and a constant atmospheric pressure. The region of the magma chamber is given by a boundary condition with a constant temperature of $900^{\circ} \mathrm{C}$. The initial distribution of rock temperature is given by an average geothermal gradient of $30^{\circ} \mathrm{C} / \mathrm{km}$. The initial distribution of fluid pressure in the array is hydrostatic. The simulation time is 40 thousand years. Spatial sampling of the model is made by means of a rectangular grid measuring $71 \times 28 \times 55$ cells with an irregular step of $100-500 \mathrm{~m}$. In total, the model contains 109,340 computational blocks. 

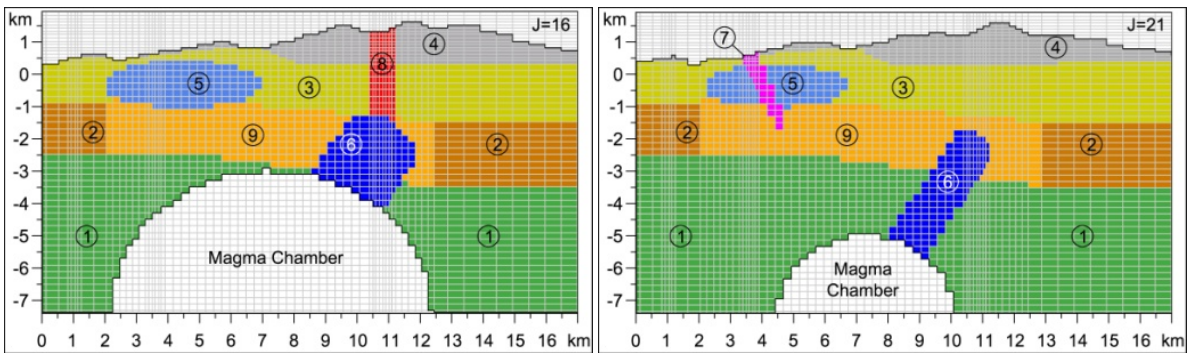

Fig. 3. Rock domains and computational grid. Left - slice through the center of Upper Koshelev field, on the right - through the center of Lower Koshelev field.

A number of numerical calculations of models with different values of rock permeability were made. The model was calibrated using four-dimensional unconditional optimization by the deformable simplex method (Nelder-Mead method). Data for the temperature in the five wells at the Lower Koshelev field were used to calibrate the models. The target function is the average linear deviation between the actual bottomhole temperature and the temperature of the calculating block corresponding to the spatial position of the bottomhole in the model:

$$
f\left(k_{3}, k_{5}, k_{7}, k_{9}\right)=\sum_{i=1}^{5}\left|T_{i}-T_{0 i}\right| / 5
$$

where $T_{i}$ - calculated bottomhole temperature; $\mathrm{T}_{0 i}-$ actual bottomhole temperature; $k_{3}$, $k_{5}, k_{7}, k_{9}$ - permeability of rock domains $3,5,7$ and 9 , respectively.

\section{Results and discussion}

In Fig. 4 shows the distribution of the temperature and the phase state of the coolant in the calibrated model. The average deviation in the wells is $30.9^{\circ} \mathrm{C}$, or $15.9 \%$.

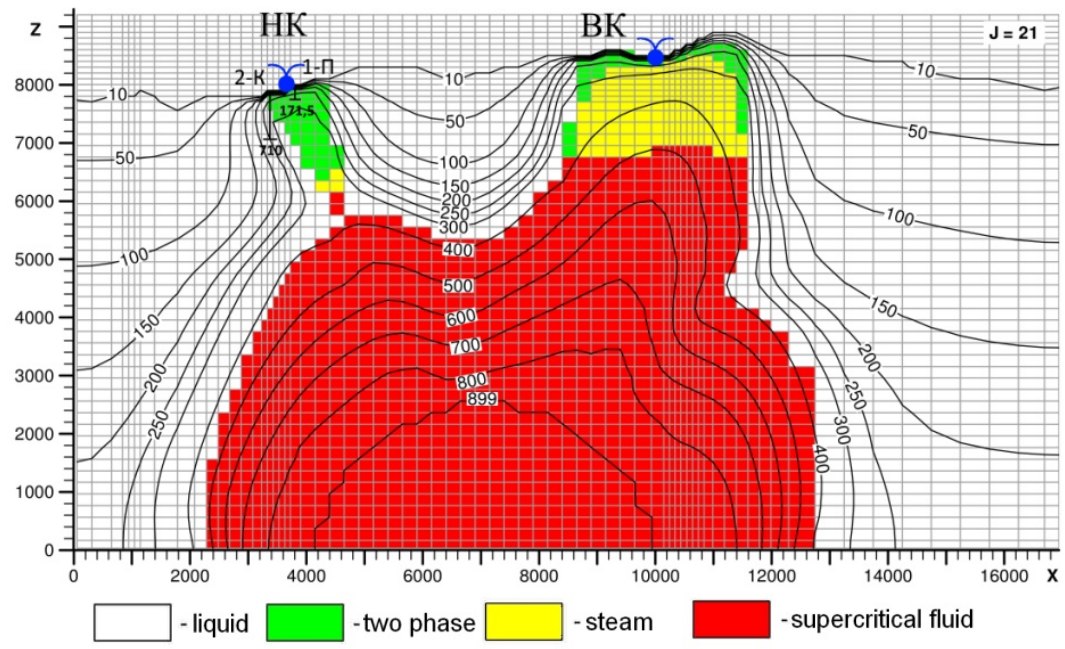

Fig. 4. Distribution of temperature $\left({ }^{\circ} \mathrm{C}\right)$ and phase state of the coolant.

The calibrated model can be used to study the spatial distribution of the thermohydrodynamic parameters of the coolant and their changes during the development of the thermal resources of the Koshelev system with the help of numerical thermo-hydrodynamic modeling. 
The results of calculating the calibrated thermo-hydrodynamic model at the final time of simulation adequately represent the distribution of thermo-hydrodynamic parameters in the system in the natural state. It used as initial conditions for determining the parameters of the coolant in the operation of the geothermal circulation system. The scheme for the development of the geothermal circulation system assumes the drilling of 6 wells with a depth of $1000 \mathrm{~m}: 3$ production and 3 injection wells. In the calculations, the temperature of the injected coolant is assumed equal to $80^{\circ} \mathrm{C}$. The specific enthalpy of the injected coolant corresponding to this temperature and the pressure at the bottom of the injection well is assumed to be $346 \mathrm{~kJ} / \mathrm{kg}$.

Thermo-hydrodynamic modeling of system operation at different values of coolant flow was carried out. Dynamics of the total thermal power of the geothermal circulation system and its impedance during operation for 30 years are shown in Fig. 5 and 6 respectively.

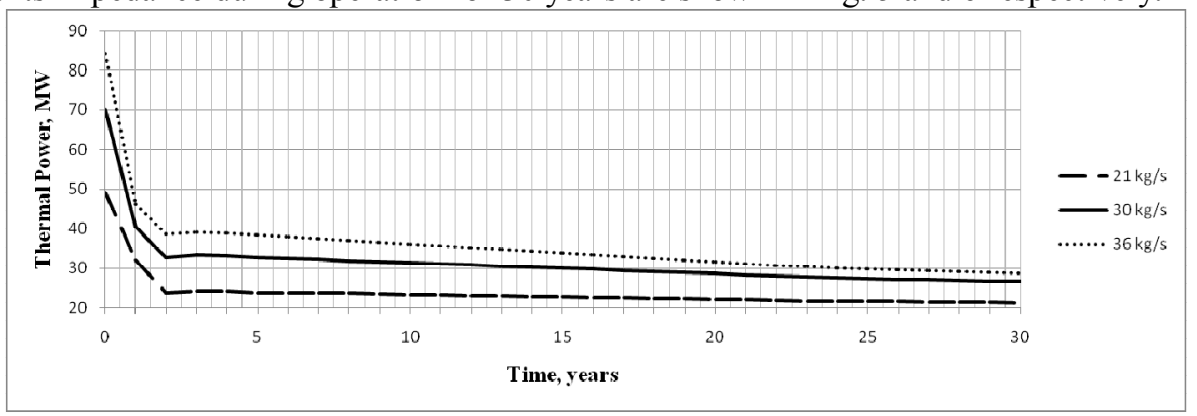

Fig. 5. Change in thermal power of the geothermal circulation system during the operating time for different values of the coolant flow rate.

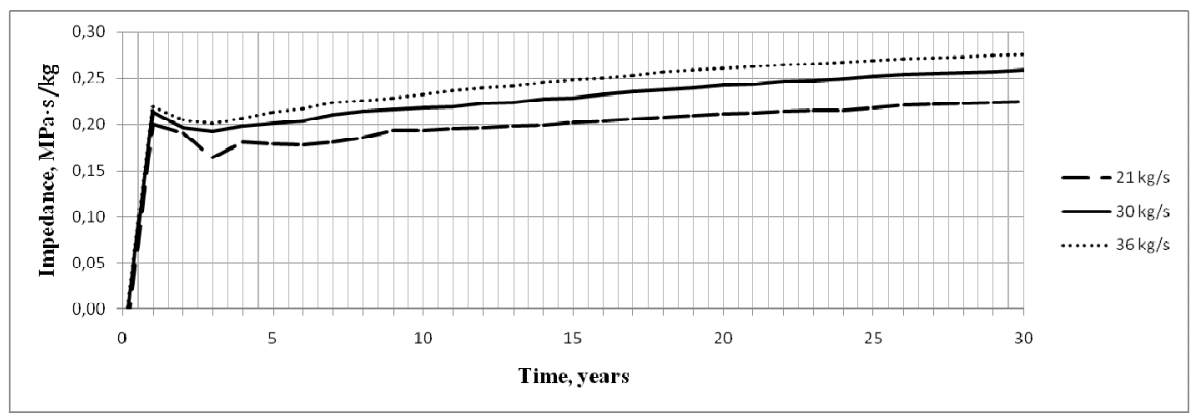

Fig. 6. Change in the impedance of the geothermal circulation system during the operating time for different values of the coolant flow rate.

During the first three years, the geothermal circulation system enters a stable operating mode. The thermal power slowly falls to $26 \mathrm{MW}$ by the end of the service life with a total flow rate of $30 \mathrm{~kg} / \mathrm{s}$. As with increasing and decreasing the flow, there is a corresponding slight change in the values of thermal power and impedance. This indicates the stability of the geothermal circulation system with small changes in the coolant flow rate.

\section{Conclusion}

The model of the Koshelev geothermal system, developed and calibrated on the basis of the available geological and geophysical data, adequately describes the distribution of thermohydrodynamic parameters of the coolant. It can be used to study the parameters of the coolant and their changes over time in the development of thermal resources. 


\section{References}

1. V.V. Averyev, Hydrothermal process in volcanic regions and its relation to magmatic activity, 118 (Moscow, 1966).

2. E.A. Vakin et al., Hydrothermal Systems and Thermal Fields of Kamchatka, 58, (Vladivostok, 1976).

3. A.I. Pozdeev et al., Volcanology and Seismology, 3, 32 (2008).

4. V.M. Sugrobov et al., Materials of the International Field Kuril-Kamchatka Seminar, July 16 - August 6, 2005 (Petropavlovsk-Kamchatsky, 2005).

5. V.M. Sugrobov, Hydrothermal Systems and Thermal Fields of Kamchatka, 267 (Vladivostok, 1976).

6. K.L. Kipp et al., Guide to the revised ground-water flow and heat transport simulator: HYDROTHERM - Version 3, 160 (Reston, 2008).

7. P.P. Blukke, et al., Detailed search for deep zones of the Lower Koshelev field of steamhydrotherms to provide the coolant for the first line of the Koshelev geothermal power plant with the capacity of 94-100 MW with preliminary exploration of its central part in 1989-1995. Book 1, 193, (Termalny, Kamchatka region, 1989).

8. V.L. Leonov, Structural conditions for localization of high-temperature fluids, 104, (Moscow, 1989).

9. M.I. Zubin, Geophysical fields and deep structure by geophysical data, Long-living center of endogenous activity of South Kamchatka, 172, (Moscow, 1980).

10. V.L. Leonov, Volcanology and Seismology, 5, 32 (2001).

11. A.V. Kiryukhin et al., Hydrogeology of Volcanoes, 395 (St. Petersburg, 2010).

12. N.E. Litasov, The active volcanoes of Kamchatka, 384 (Moscow, 1991).

13. M.V. Pisareva, Volcanology and Seismology, 2, 52 (1987).

14. V.V. Shanina et al., Geoecology. Engineering geology. Hydrogeology. Geocryology, 5, 459 (2013).

15. V.V. Shanina et al., Water: Chemistry and Ecology, 1, 3 (2015).

16. F.A. Yanovsky, Volcanology and Seismology, 5, 77 (1989).

17. N.B. Dortman et al., Physical properties of rocks and minerals (petrophysics).

Handbook of Geophysics, 527 (Moscow, 1976).

18. V.N. Kobranova, Physical properties of rocks, 470 (Moscow, 1962). 